\title{
Dynamic Performance of a Microturbine Connected to a Low Voltage Network
}

\author{
E. Torres ${ }^{1}$, J.M. Larragueta ${ }^{1}$, P.Eguia ${ }^{1}$, J. Mazón ${ }^{1}$, J.I. San Martín ${ }^{2}$ and I. Zamora ${ }^{1}$ \\ ${ }^{1}$ Department of Electrical Engineering \\ E.T.S.I.-Bilbao, UPV/EHU \\ Alda. Urquijo s/n , 48013 Bilbao (Spain) \\ Phone number:+0034 94 6017332, e-mail: esther.torresi@ehu.es \\ ${ }^{2}$ Department of Electrical Engineering \\ E.U.I.T.I.-Eibar, UPV/EHU \\ Av. Otaola 29, 20600 Eibar (Spain) \\ e-mail: iepsadij@sb.ehu.es
}

\begin{abstract}
Nowadays there is a great interest for the use of microturbines as sources of distributed generation, particularly in areas where demand is both electricity and heat. In these areas microturbines reach very high efficiency rates.

Microturbines can operate both stand-alone and grid connected. The second one of the mentioned possibilities is which deserves a much deeper study, to analyse the interaction of the microturbine with the distribution network it is connected to.

In this paper a dynamic model of a microturbine is developed with Matlab/Simulink/Simpowersystems. The model has been included within a low voltage network model and several dynamic simulations have been performed to study the response to step changes in the power control references. Also, the performance of the microturbine to faults in the network has been analysed.
\end{abstract}

\section{Key words}

Distributed generation, Microturbine, Dynamic model, Simulation.

\section{Introduction}

In recent years, the search for generation systems more efficient and less harmful to the environment have helped to introduce distributed generation within the electric networks, as opposed to the traditional large generation plants.

Traditional power plants involve high investment and maintenance costs and the energy produced must be delivered across long transmission lines with losses of about $2 \%$ of the energy transmitted. In addition, nowadays there is also a strong social rejection to the extension of traditional generation.

In contrast, distributed generators are small power plants, with lower costs than traditional units. This type of generation is mainly connected to the distribution network, which implies smaller network losses. It is also frequently based on renewable resources so they have a lower environmental impact than traditional generation.

Combined heat and power or cogeneration is, at present, the most significant type of distributed generation. The simultaneous production of electrical power and useful heat at the location where they are to be consumed increases the overall efficiency in the use of fuel. There are different technologies for combined heat and power. One of them is based on the use of microturbines, which allows to reach overall thermal efficiencies of around $90 \%$.

Microturbines can operate both stand-alone and grid connected. The second one deserves a much deeper study, to analyse the interaction between the microturbine and the distribution network it is connected to. The connection of microturbines to the current medium and low voltage distribution networks modifies the electrical parameters in the network operation, as distribution networks were designed for radial operation and supply from a power transformer located at the sending end.

In addition to the modifications in the voltage profile and the influence on power losses, the modification both in fault levels and in the distribution of fault currents must be considered. This is an aspect that needs to be studied because the network protection scheme may be affected, being influenced both the individual operation of each existing protection device and their coordination.

This paper analyses the connection of microturbines to the low voltage distribution network from the viewpoint of its transient behaviour during fault situations. With this purpose, a microturbine model is developed to carry out dynamic studies and to analyse the microturbine performance when it is connected to the network under different fault conditions. 


\section{Gas Microturbines}

Microturbines are small combustion turbines, with installed capacity from 25 to $300 \mathrm{~kW}$ and very high rotation speeds (between 50.000 and $120.000 \mathrm{rpm}$ ). They can be used as a support device to satisfy demand peaks, or as distributed generator in microgrids. Table I shows the more important characteristics of various microturbine models.

Table I. Microturbines characteristics

\begin{tabular}{|c|c|c|c|c|c|c|}
\hline & $\begin{array}{l}\text { Electric } \\
\text { Power }\end{array}$ & $\begin{array}{c}\text { Fulul } \\
\text { Cumsumption }\end{array}$ & \begin{tabular}{|c} 
Electric \\
Efficiency
\end{tabular} & $\begin{array}{l}\text { Exhaulst } \\
\text { Gas Flow }\end{array}$ & \begin{tabular}{|c|} 
Termal \\
Recovered \\
Power \\
\end{tabular} & $\begin{array}{l}\text { Nox } \\
\text { Emissions }\end{array}$ \\
\hline Capston C 30 LP & $28 \mathrm{kWW}$ & $113 \mathrm{kWW}$ & $25 \%$ & $0.31 \mathrm{~kg} / \mathrm{s}$ & $60 \mathrm{KWW}$ & $0.22 \mathrm{~kg} M \mathrm{MWh}$ \\
\hline Capston C 30 HP & $30 \mathrm{kWW}$ & $115 \mathrm{KWW}$ & $20 \%$ & $0.31 \mathrm{~kg} / \mathrm{s}$ & $60 \mathrm{kWH}$ & $\$ 1.22 \mathrm{kgMMWh}$ \\
\hline Capston C6O & $60 \mathrm{kWW}$ & $211 \mathrm{kWN}$ & $28 \%$ & $0.49 \mathrm{~kg} / \mathrm{s}$ & $110 \mathrm{kWW}$ & $\$ 1.22 \mathrm{kgMMWh}$ \\
\hline Tubec 7100 & $105 \mathrm{kWW}$ & $350 \mathrm{kWW}$ & $30 \%$ & $0.00 \mathrm{~kg} / \mathrm{s}$ & $167 \mathrm{kWW}$ & $<15 \mathrm{ppm} / \mathrm{y}$ \\
\hline Bouman TG80 & $80 \mathrm{kWW}$ & $285 \mathrm{KWW}$ & $27 \%$ & $0.83 \mathrm{~kg} / \mathrm{s}$ & $150 \mathrm{kWW}$ & N.A. \\
\hline
\end{tabular}

Microturbines can work according to a simple or a regenerative cycle. In the first one, of lower cost, compressed air is mixed with fuel and the combustion is carried out under constant pressure. Hot gases expand inside the turbine producing work. The regenerative cycle requires an interchanger to recover exit turbine heat and transfer it to the air entrance. The preheated air is used lately in the combustion process, saving between $30 \%$ and $40 \%$ of fuel [3-4]. The combination of microturbines with energy recover equipments allows duplicating the electric efficiency with respect to simple cycle microturbines. Figure 1 presents a block diagram of a microturbine with regenerative cycle.

Microturbines have got regulation units that allow doing the following functions: control of the fuel flow, adaptation of the electrical signals for their use in the conventional electric network, voltage and frequency regulation, etc.

It usually has sealed batteries that can be recharged with commercial chargers or connection to the network. They allow managing the power transients, supplying electric energy during high peaks and absorbing energy when power decreases quickly.

Different fuels can be used: natural gas, LPG (commercial butane and propane), diesel, kerosene, biogas, hydrogen, etc. Besides, related to air emissions, they are very low when operating at full load or even above $60-70 \%$ of full load. The main primary pollutants emitted by microturbines are nitrogen oxides $\mathrm{NO}_{\mathrm{X}}$ and carbon monoxide $\mathrm{CO}$. $\mathrm{CO}$ emissions are strongly dependent of the load operation, showing peaks during the starting up.

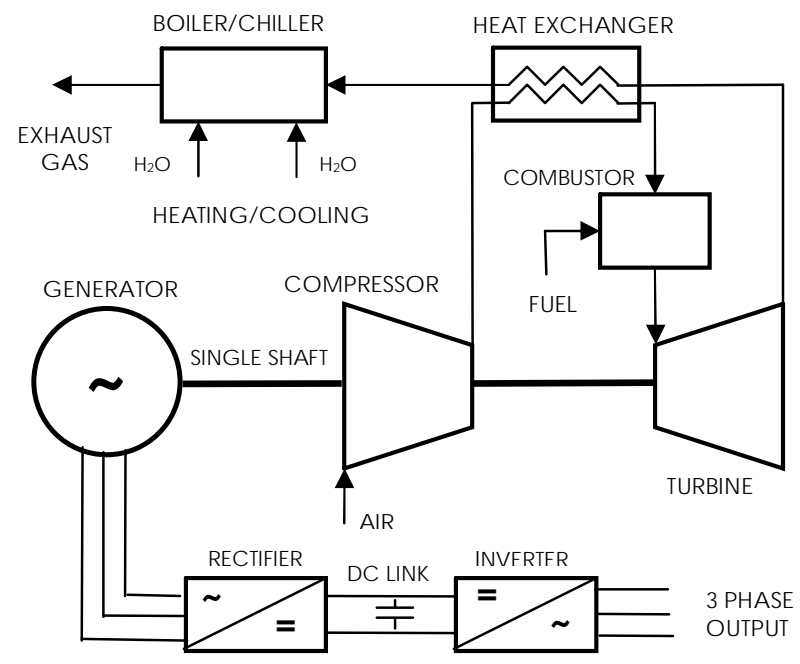

Figure 1. Gas microturbine operation scheme

Brayton thermodynamic cycle with regeneration, allows giving the expression of the thermal efficiency (1)

$$
\eta=1-\frac{r^{\left(\frac{\gamma-1}{\gamma}\right)}}{t}
$$

Efficiency $(\eta)$ depends strongly on the pressures ratio (r), typology of gas $(\gamma=\mathrm{Cp} / \mathrm{Cv})$ and the temperatures ratio $\left(\mathrm{t}=\mathrm{T}_{3} / \mathrm{T}_{1}\right)$. With $3<\mathrm{r}<5$, efficiencies above $60 \%$ are obtained. These ' $r$ ' values are low compared with the big machines ones, and therefore the axial compressors are not justified.

The Electric Efficiency is defined as the quotient between electric power supplied to the network or loads $(\mathrm{kW})$ and the gas consumption $(\mathrm{kg} / \mathrm{h})$. In [5], graphical results are presented to different temperatures and it is observed that the fuel consumption is lower at lower temperatures and consequently the microturbine efficiency increases. Also, it can be appreciated that the electric efficiency decreases considerably with the output power, so it seems advisable working at full load during most of the time. In this kind of tests, batteries can be used only to start up under "black start" conditions and to cover the load peaks during the transient periods, but not to provide additional energy during a normal operation.

The Thermal Power is the heat power recovered from the microturbine outlet as hot water. This hot water can be used for heating of buildings, production of industrial cold, etc.

The Global Efficiency is defined as the quotient between the sum of electric output power (We) and heat power recovered (Qhr) to the heat power supplied for the natural gas (Qf) (2). 


$$
E_{g}=\frac{W_{e}+Q_{h r}}{Q_{f}}
$$

Numerical analysis developed for different ambient temperatures [5] show that efficiencies increase notably at colder temperatures. On the other hand, although the electric efficiency of the gas microturbine is lower than the corresponding to industrial gas turbines, it must be kept in mind that microturbines will be used mainly in combined systems (thermal and electric power) and the global efficiency parameter plays an important role in this case.

Additionally, a key parameter to define power quality of the generated energy is the harmonic content in the generated signal. Analyses developed for different public and private entities show a light distortion in the voltage and current waveforms (third harmonic), although the power generated complies with the voltage distortion limits indicated in standards [6-7]. It can also be observed that with low loads, waveform has a bigger but not very significant distortion. Finally, no fluctuations in voltage stability have been recorded in any test at any electrical load. No difference has been found between the power quality supplied when the turbine is operated stand-alone or grid connected.

\section{Microturbine Dynamic Model}

This section describes the dynamic model of the microturbine. The model incorporates the AC/AC VSC converter and the primary motor as well as the controls associated with both components. Figure 2 shows a simplified model of the microturbine structure.

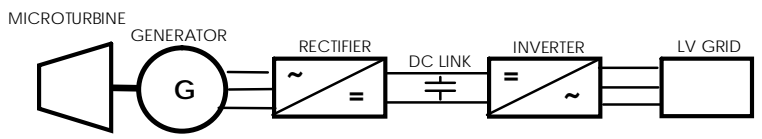

Figure 2. Microturbine model

The model is based on the Capstone C30HP microturbine [18-19], whose characteristics are shown in Table II.

TABLE II. Capstone C30HP main characteristics

\begin{tabular}{|l|l|}
\hline Electrical Power Output & $30 \mathrm{~kW}$ \\
\hline Electric Efficiency & $26 \%$ \\
\hline Voltage & $400-480 \mathrm{~V}$ \\
\hline Frequency & $50 / 60 \mathrm{~Hz}$ Grid Connected \\
& $10-60 \mathrm{~Hz}$ Stand Alone \\
\hline Maximum Output Current & $46 \mathrm{~A} \mathrm{Grid} \mathrm{Connected}$ \\
& $54 \mathrm{~A} \mathrm{Stand} \mathrm{Alone}$ \\
\hline Natural Gas Consumption & $115 \mathrm{~kW}$ \\
\hline Exhaust Gas Flow & $0,31 \mathrm{~kg} / \mathrm{s}$ \\
\hline Exhaust Gas Temperature & $275^{\circ} \mathrm{C}$ \\
\hline Termal Power Output & $60 \mathrm{~kW}$ \\
\hline NO $_{\mathrm{X}}$ Emissions & $0,22 \mathrm{~kg} / \mathrm{MWh}$ \\
\hline Speed & $96.000 \mathrm{rpm}$ \\
\hline
\end{tabular}

\section{A. Microturbine}

A dynamic model for a combustion gas turbine is widely discussed in [10-11]. In this research a simplified single shaft gas turbine has been implemented to represent its dynamics, with a power output reference as input and rotor speed as output.

\section{B. Electric Generator}

The mechanical power generated drives a permanent magnet synchronous generator (PMSG). The permanent magnets supply to the generator the excitation, replacing the conventional DC field winding of rotor, thus eliminating problems such as brush/slip ring system or copper losses in the excitation system. The study and development of new magnetic materials, such as neodyum-iron-boron or salarium-cobalt, have made possible to obtain more powerful and compact magnets, capable of being used in multiple applications, such as generators for microgeneration.

The PMSG model used in this study consists of a nonsalient rotor directly linked to the microturbine gas shaft, with two poles. Its power is $30 \mathrm{~kW}$, reaching speeds up to $96,000 \mathrm{rpm}$. On this way the generator provides a threephase variable frequency signal up to $1600 \mathrm{~Hz}$ and a voltage level between 400 and $480 \mathrm{~V}$.

For the model of PMSG their mechanical and electrical equations have been used, obtaining a second-order statespace model. The model considers that the permanent magnets generate a sinusoidal magnetic field, wich implies that the electromotive forces are also sinusoidal. In the electrical equations of the model, the currents and voltages are expressed in the rotor dq-frame, being translated to the abc-frame through the Park Transform. The mechanical and electrical equations can be taken from [13-14].

\section{Power Conditioner System}

The variable frecuency signal provided by the generator must be converted by a power electronic system to connect to the low-voltage distribution grid $(50-60 \mathrm{~Hz})$. The system consists of a uncontrolled three-phase rectifier, and a voltage source inverter, interconnected by a DC-link.

The three-phase rectifier converts the high-frecuency signal to DC signal. For the model, it has been chosen a three-phase diode rectifier for being a simple model which does not require a control unit. The dc link is composed of a capacitor to reduce the ripple of the DC signal.

The DC signal is converted to low frecuency AC voltage by a voltage source inverter (VSI). The VSI is implemented with IGBT transistors (Insulated Gate Bipolar Transistor), which are capable of working at high frequency with low switching losses. This has made them to be the most commonly used semiconductor in 
distribution voltage level, especially in inverters. The set of IGBT transistors with its protection circuits (snubbers) are integrated into a block, called IPM (Intelligent Power Modules). The output voltage of the VSI is achieved using the procedure called pulse width modulation (PWM).

In order to control the grid connected microturbine a PQ control strategy has been used, where the inverter must control active and reactive power. To implement this control a dq-reference frame is used, which decouples the active and reactive power in order to make two independent control loops, extensively described in [1216-17].

On one hand, the active power control loop, regulates the $\mathrm{DC}$ bus voltage with a PI controller from a $\mathrm{V}_{\mathrm{DC} \text { ref }}$ setpoint. On the other hand, the reactive power control loop, regulates the $i_{q}$ current with a PI controller from a $i_{q}$ ref set-point, which should be 0 when reactive power is not required.

A phase lock loop (PLL) is used to implement the park transformer for the $\mathrm{dq}$ frame, synchronizing the converter with the grid. The control scheme is shown in the Figure 3.

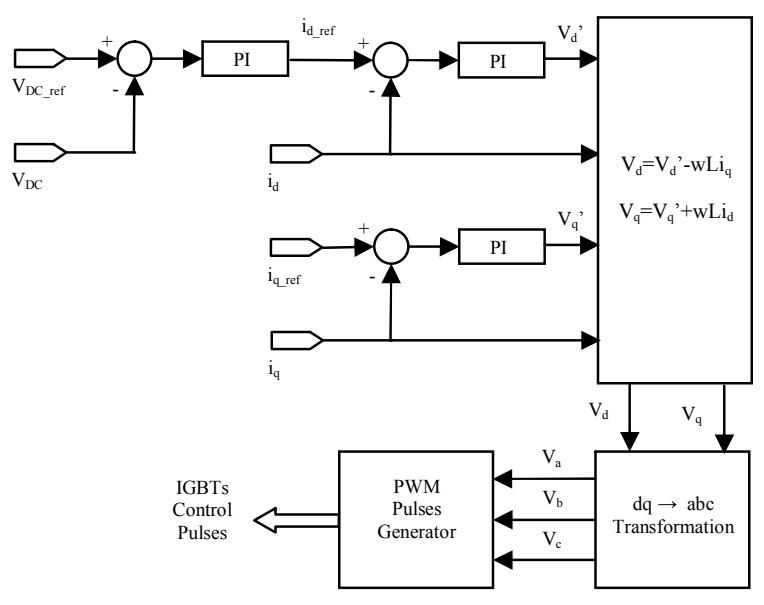

Figure 3. VSI control scheme

The output signal of the inverter contains high frecuency components generated by the high frecuency operation of the inverter, so a LC filter is placed at the microturbine output terminals.

The microturbine operates in the grid connected mode, connected to a low-voltage distribution grid $(400 \mathrm{~V}, 50$ $\mathrm{Hz}$ ), which is modelled as an infinite bus. Finally, the model is completed with a three phase load and a fault block. Figure 4 shows the developed model with the elements previously described.

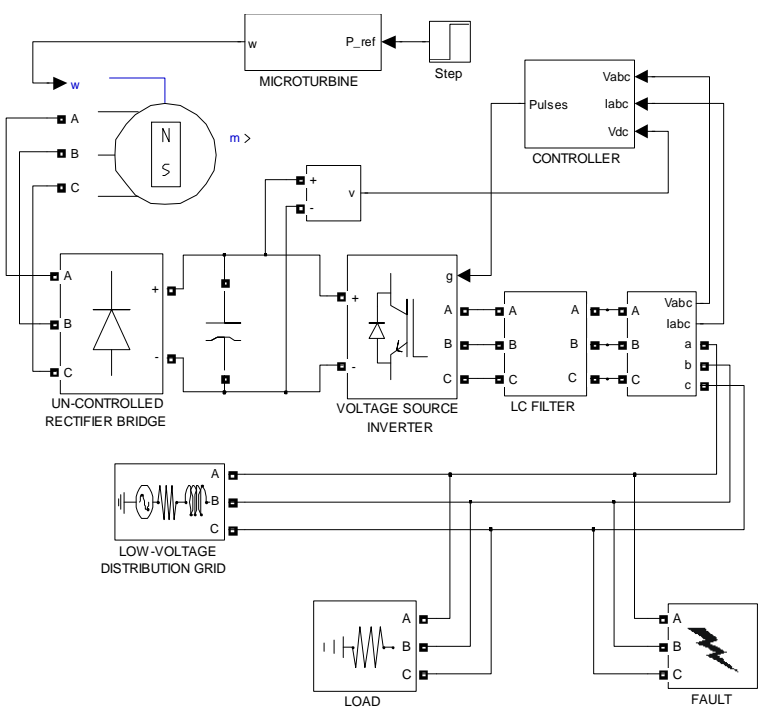

Figure 4. Matlab/Simulink microturbine model

\section{Simulation and results}

Simulation has been performed in order to study the response of the grid connected microturbine to a variation in the power set-point, as well as the microturbine response with a three phase fault produced at the output terminals. Simulations have been run in discrete time with a fixed-step size of $0.5 \mu \mathrm{seg}$.

\section{A. Step increase in power set-point}

In this first simulation, the microturbine is working in floating mode, when the power set-point is increased from 0 to $20 \mathrm{~kW}$ at $\mathrm{t}=1 \mathrm{seg}$ (green line). Figure 5 shows the response of the microturbine, which increases its active power output to deliver $20 \mathrm{~kW}$.

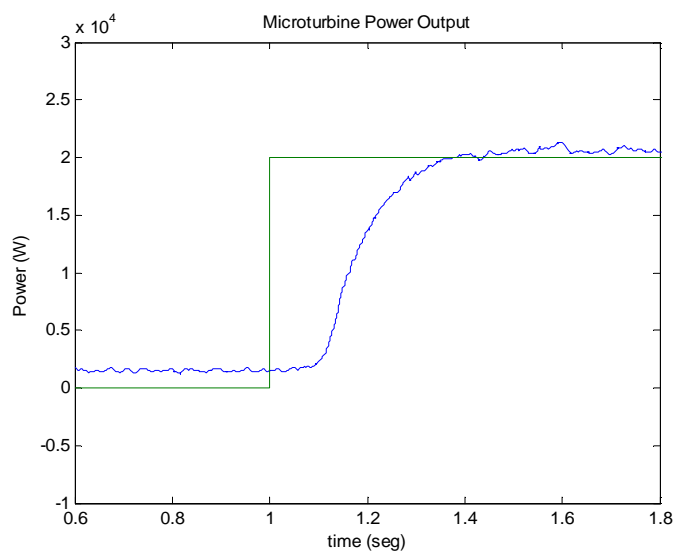

Figure 5. Active power output of microturbine with power setpoint increase

Figures 6 and 8 show the three phase voltage and current at microturbine terminals. Figures 7 and 9 show the voltage and current corresponding to the phase A (colored blue), and their $50 \mathrm{~Hz}$ fundamental components 
(colored green), where the similarity of the signal generated by the inverter with the LV grid signal reference can be seen.

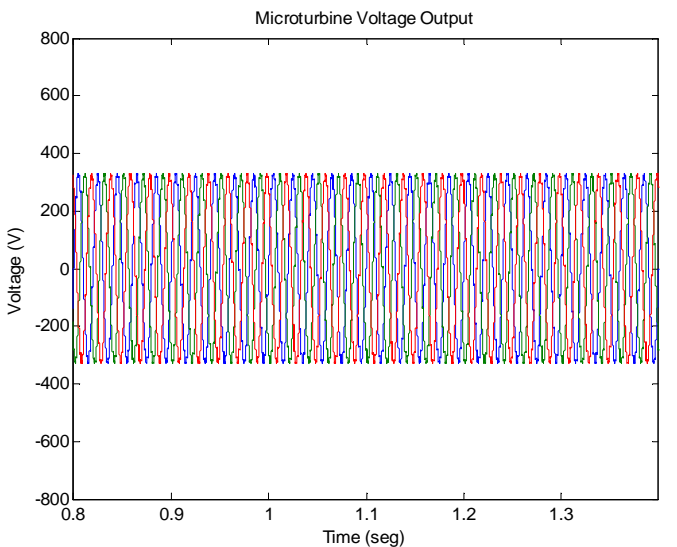

Figure 6 . Voltage output of microturbine with power set-point increase

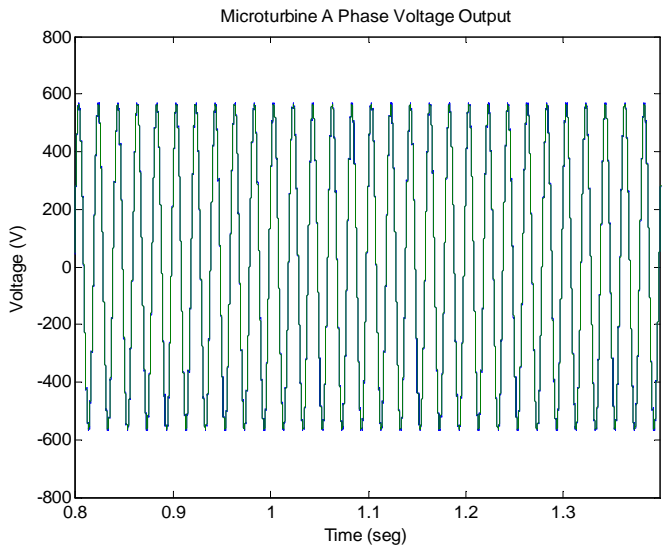

Figure 7. Phase A voltage output of microturbine with power set-point increase

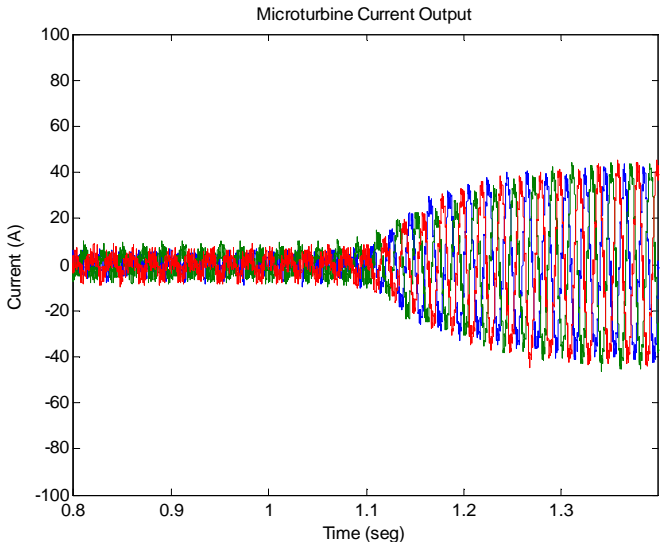

Figure 8. Current output of microturbine with power set-point increase

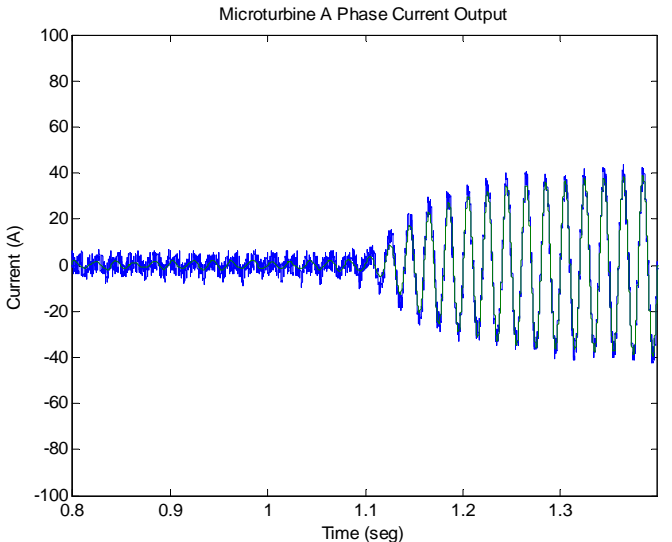

Figure 9. Phase A current output of microturbine with power set-point increase

\section{B. Three phase fault}

In this simulation case, a three phase fault is generated at the output terminal of the microturbine at $\mathrm{t}=1.9 \mathrm{seg}$. Figures 10 and 11 show active power and the voltage in the microturbine output terminals. The voltage decreases strongly because of the fault and this causes the active power output to fall. Figure 12 shows the fault current generated.

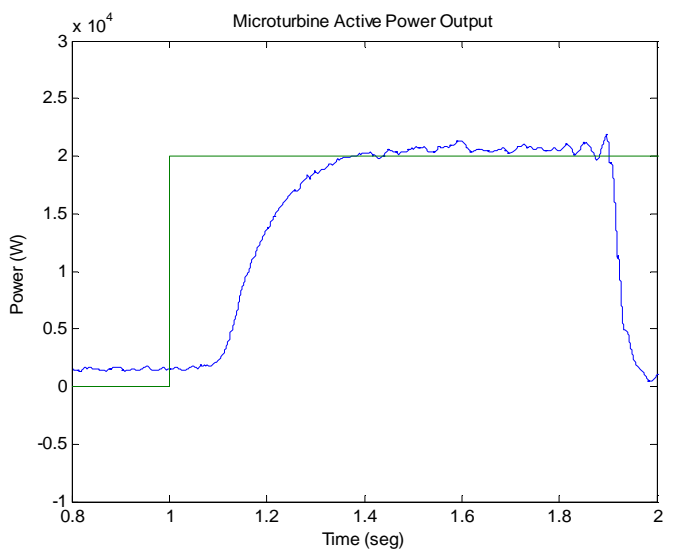

Figure 10. Active power output of microturbine with a three phase fault

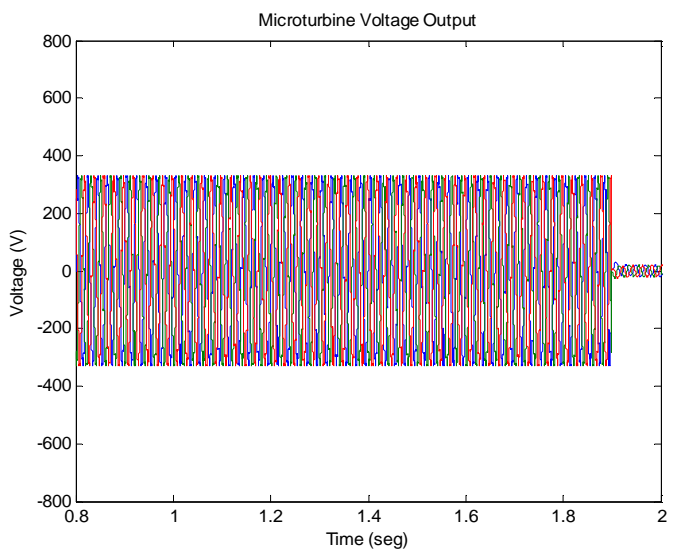

Figure 11. Voltage output of microturbine with a three phase fault 


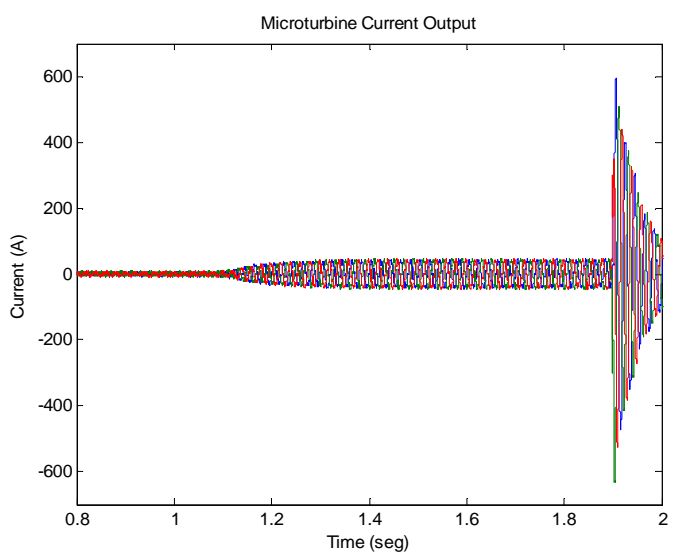

Figure 12. Current output of microturbine with a three phase fault

\section{Conclusions}

A microturbine simplified model has been developed by using Matlab/Simulink/Simpowersystems software. The model has been simulated working in grid connected mode and different operation conditions have been analysed (Step change, fault,...). The simulation results have showed that the microturbine works properly connected to a low voltage distribution grid. Next developments in this field will be the improvement and optimization of the microturbine model as well as the analysis of multiple operation conditions, mainly related to different fault situations and the definition of the settings of protection relays.

\section{Acknowledgements}

The work presented in this paper has been carried out by the research team of Project ENE2006-15700-CO2$02 / \mathrm{CON}$, supported by the Ministry of Education and Science of Spain.

\section{References}

[1] G. Strbac, "Electric power systems research on dispersed generation", Electric Power System Research, Vol. 77, pp. 1143-1147, 2007.

[2] S.barsali, M.Ceraolo, R.Giglioli, P.Pelacchi, "Microturbines for dispersed generation", CIRED, Nice France, 1999.

[3] P.A.Pilavachi, "Mini and Micro-gas Turbines for Combined Heat and Power". Applied Thermal Engineering, Vol.22, pp. 2003-2014, 2002.

[4] M.Nagpal, A.Moshref, G.K. Morison, et al., "Experience with testing and modelling of gas turbines", Proceedings of the IEEE/PES 2001 Winter Meeting, pp. 652-656, Columbus, Ohio, USA, January/February 2001.

[5] J.C.Bruno, LI.Massagués, A.Coronas; "Power Quality and Air Emission Tests in a Micro Gas Turbines Cogeneration Plant". International
Conference on Renewable Energy and Power Quality. Vigo, Spain. 2003.

[6] 519-IEEE, "Recommended Practices and Requirements for Harmonic Control in Electrical Power Systems", 1992.

[7] CENELEC EN-50160 "Voltage Characteristics of Electricity Supplied by Public Distribution Systems", 1999.

[8] N. Jenkins et al., "Embedded generation", The Institution of Electrical Engineers, London, 2000.

[9] B.F. Kolanowski, "Guide to microturbines", Ed. Marcel Dekker, New York, 2004.

[10] W.I.Rowen, "Simplified mathematical representations of a heavy duty gas turbines", ASME Trans. Journal of Engineering for Power, Vol. 105, no. 4, pp.865-869, Oct. 1983.

[11] S.Banetta, M.Ippolito, D.Poli, A,Possenti, “A Model of Cogeneration Plants Based on Small-Size Gas Turbine", CIRED.16th International Conference and Exhibition, Amsterdam, 2001, Vol.1, pp. 266.

[12] A.Bertani, C.Bossi, F.Fornari, S.Massuco, S.spelta, F.Tivegna, "A Microturbine Generation System for Grid Connected and Islanding Operation", Power Systems Conference and Exposition, 2004. IEEE PES, Oct. 2004, Vol. 1, pp. $360-365$.

[13]D.N.Gaonkar, R.N.Patel, "Modelling and Simulation of Microturbine Based Distributed Generation System", Power India Conference. 2006 IEEE, April 2006.

[14] D.N.Gaonkar, R.N.Patel, "Dynamic Model of Microturbine Generation System for Grid Connected/Islanding Operation", Industrial Technology, 2006. ICIT 2006. IEEE International Conference, Mumbai, India, Dec. 2006, pp. 305310.

[15] W.G.Rioja, M.G.Molina, P.E.Mercado, W.I,Suemitsu, "Dynamic Model of a Gas Microturbine for Distributed Generation in Simpowersystems of Matlab/Simulink", $9^{\text {th }}$ Bazilian Power Electronics Conference COBEP2007, Oct.2007, pp. 747-752.

[16]H. Nikkhajoei, R. Iravani, "Electromagnetic transients of a micro-turbine based distributed generation system", Electric Power Systems Research, Vol. 77, pp. 1475-1482, 2007.

[17]H. Nikkhajoei, R. Iravani, "Dynamic Model and Control of AC-DC-AC voltage-sourced converter system for distributed resources", IEEE Transactions on Power Delivery, Vol. 22, No. 2, pp. 1169-1178, April 2007.

[18]F.E.Pierce, "Summary of Results from Testing a $30 \mathrm{~kW}$ Microturbine and Combined Heat and Power (CHP) System", Federal Energy Management Program - U.S. Department of Energy, DOE/EE0316, May 2007

[19]www.capstoneturbine.com

[20]www.mathworks.com 